\title{
Research on the College Students' Psychological Health Education Model under Internet Environment
}

\author{
Yumei Jing \\ Hubei Normal university, HuBei HuangShi, 435000, China.
}

Keywords: Psychological Health, Education Model, Internet Environment, College Students.

\begin{abstract}
This paper conducts research on the college students' psychological health education model under Internet environment. The rapid development of network technology and widely used, not only played a great role in promoting the development of the society, but also to the college students' psychological health and psychological development of comprehensive significant impact. Important, because the network is not perfect, immature, and network management, network society morals be regulated, the impact of network on college students' mental health and the negative effect became more and more obvious, some college students obsessed with the network, to develop the network syndrome, leading to political ideas, ideology westernised, ethical and moral anomie, psychological closed, etc. This paper starts from the analysis of the real-world condition of the related issues to propose the new idea on the related challenges that will be meaningful.
\end{abstract}

\section{Introduction}

To implement and promote all-round quality education, it is long-term education reform and the development in China is facing a major task and the main melody. One of the important content of the quality education and task is to make the students form good psychological quality and improve the students' mental health. College students' mental health education, mental health education and the height of the students' ideological and political work coordination, not only can reduce the college students' psychological disorders and improve the level of mental health, optimize the psychological qualities, but also help promoting orderly and efficient development of ideological and political work in colleges and universities which holds the following advantages [1,2].

- To strengthen college students' mental health education is conducive to the healthy growth of the college students. With the development of the society, college students are faced with the social environment, family environment and the problems in the process of growth is more complex, diverse and specific, the development of college students especially the pressure of competition pressure, the study pressure, economic pressure, employment pressure, emotional pressure generally increased, the resulting psychological problems are increasing.

- To strengthen college students' mental health education is helpful and essential to therefore comprehensively promote quality education. Practice has proved that the psychological quality is the basis of talent quality, college students don't have basic psychological quality can't complete their studies very well more cannot afford the responsibility of the construction of the motherland in the future.

- To strengthen college students' mental health education is helpful for strengthening and for improving moral education in colleges and universities. At present, with the development of the socialist market economy, the situation of the moral education work in colleges and the universities is facing more complex, and more heavy and hard task.

University mental health education under the Internet environment refers to the psychological health education based on Internet environment, it is using the openness of the network environment and virtual feature, equality and the interaction, puts forward the Internet as the new mental health education in institutions of higher learning, new tools and new methods, to improve and promote the mental health education system that is a new mode of psychological health education. Therefore, to strengthen college students' mental health education is imperative. And with the rapid development of information technology, the influence of the Internet, with its irresistible, to reach into every field 
of social life, the Internet is changing the students' learning and way of life as the profound influence on their mental health, but also to the psychological health education work that has brought the new opportunities and new challenges. For further analysis and research, in the figure one, we demonstrate the brain nerve function distribution pattern [3].

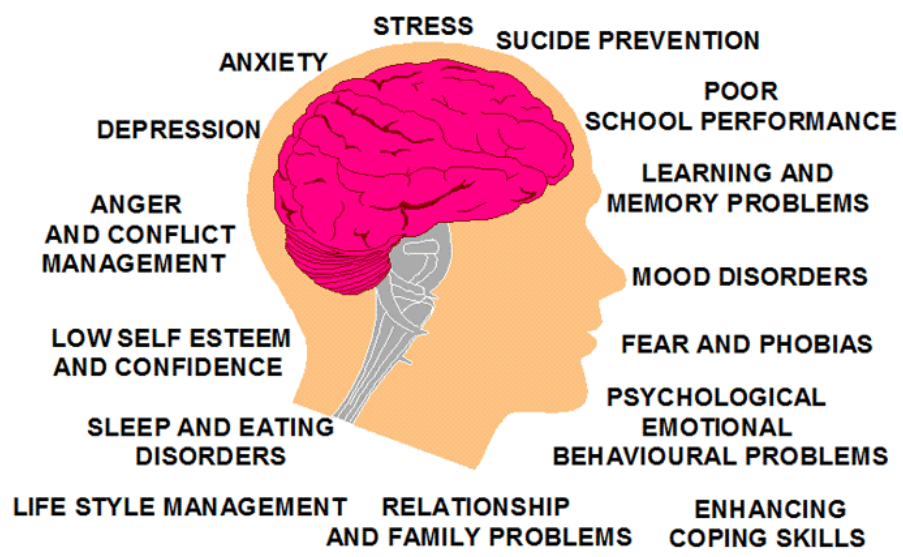

Fig. 1 The Demonstration of the Brain Nerve Function Distribution

Under this basis, in this paper, we conduct research on the college students' psychological health education model under Internet environment. In the later sections, we will discuss in detail.

\section{Our Proposed Methodology}

\subsection{University Students' Education Principles.}

College student education management pattern to develop structure complicated while education management specialization and a series of new changes, new features and new requirements. Explore the effective management of college student education mode that becomes urgent to strengthen and improve ideological and political education work. From the point of college education management team, with an increasing number of students enrollment in colleges and universities, the greater the transactional workload management of college students education, and more complex diverse, in addition to the daily management of the school each department mostly fell upon the education workers at the local, it's affected the main direction of the related work, weaken the work of its intended effect, lead to job performance is difficult to reflect, leading to career fulfillment is not high, work enthusiasm.

Therefore, it is necessary in combination with the current actual situation, to re-examine the nature of managing college students' education in the new period implications, explore new type of college students education management mode, to cope with the present college education is faced with the series of new changes. How to solve these problems, to explore a solution in the practical work is the university student management work is an urgent need to solve the problem as follows.

- Emphasis on discipline and order in the process of teaching and view of management and the ideological education work correctly, in the view with the thoughts and modes of the school student work, etc. can make students realize the to obtain professional knowledge not only in class that also want to accept management education and ideological education.

- To strengthen students' daily behavior management under the premise of institutionalization, standardization, deep thinking to students as the main body of management mode. The rules and regulations to standardize the behavior of the college students that create a positive educational atmosphere as cultivating college students' character and form the habit of the discipline and personality characteristics is indispensable means.

- In the actual process of student management, how to obtain a better management effect that should make some of text on the institutional construction, while especially the ideological education of the institutionalized management. Thought was the forerunner of action, and action to specification by management. 
Education choice in essence is the pursuit of the interests of the individual education behavior, highlight the personal interests of the market economy is the spirit reflected in the field of education. The individual education choice is the behavior of the educatees intends to express are apparent to the interests of the people. Education in the sense of the option refers to the students as the main body of education resources and the right to choose their learning style and freedom. Students of the higher education needs are the premise and basis of students of higher education choice, students of higher education choice is the way of demand to meet that is a personal right and true education.

\subsection{Psychological Health Education Principles.}

Mental health education in class activities as the main form, in the face of all the students and the teaching activities, it is the overall goal of all the students as the object, according to the rules of the development of the students' psychological and personality psychological characteristics, purposeful, planned, step by step to improve the students' psychological quality, stimulate potential and healthy personality and enhance the ability to withstand setbacks and environmental adaptation, so that the students can fully know themselves, know others objectively, can fully exert self-potential with good social adaptation, learning, life, will survive and will create individual [4].

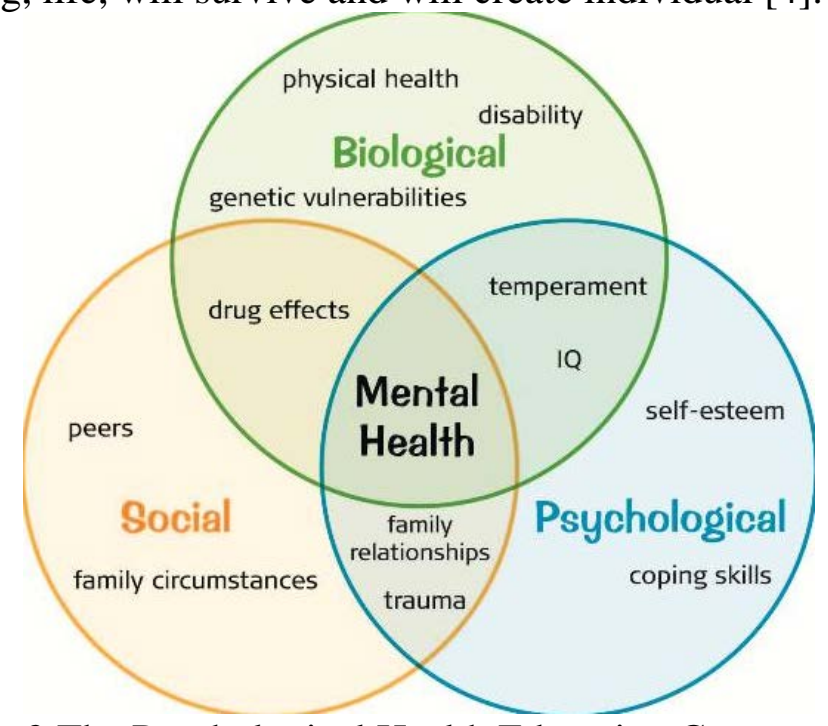

Fig. 2 The Psychological Health Education Components

The mental health education, the school must know what is meaning of mental health? And to understand the mental health, must accurately grasp the health and mental hygiene two concepts.

- Mental hygiene. Mental health and mental health that relative to the physical health. Original intention is to maintain and improve mental health, reduce the psychological and behavioral problems and disease. The meaning of it in addition to refer to a discipline and a service work, also points to people's mental health and the state, in short, synonymous of mental health and the general mental health.

- Mental health. Refers to mental health, refers to the physical, intellectual and emotional and others, within the scope of the mental health is not contradictory to develop personal mood into the best state. Embodied in: physical, mental, emotional very coordination as to adapt to the environment, interpersonal relationships can self-effacing each other; Have happiness in jobs and careers can give full play to their abilities, productive life.

It is the psychological counseling in the value of moral education in colleges and universities, the contribution of psychological consultation to moral education in colleges and universities to meet the school needs to cultivate college students' ideological and moral quality, psychological counseling is valuable in the moral education in colleges and universities, its value respectively from status, with function, process, results, and the general significance of the five aspects.

\subsection{Internet Psychological Health.}

In the study of Internet psychology, Internet use behavior and consumer related social problem of the relationship between the mental health is always more attention from the researchers. Weiser 
Internet use motives as intermediary factors are obviously unreasonable. Secondly, the model will only personal Internet time and work time online as indices of Internet use behavior, think that the former is mainly related to pathological Internet use behavior, while the latter belongs to the normal use of behavior of the Internet. The author thinks that, Internet use motivation differences could cause different Internet use behavior model, which can lead to users of different social psychological effect. In Internet use motivation, behavior and social psychological effect system, Internet use motivation is the starting factors of Internet use behavior, and Internet use behavior is Internet use motives and consumer society intermediary variables between the heart health based on the above assumptions, this research aims to Internet use motives and combined use of actions and their consequences, trying to build a more effective and more integrated model.

Network culture has on the college students' learning, life, work and way of thinking produced extensive and profound influence, ideological and political work personnel to student's thought political education work must come to the network, to understand the inner world of college students and dynamic ideas. So to strengthen the ideological and political education network technology and the network of psychological training for the staff, enabling them to use network this platform equal exchange and communication with college students, can use the network to carry out the interesting of the ideological and moral education, to adapt to the network era of ideological and political education work puts forward new requirements.

\section{Conclusion}

In this paper, we conduct research on the college students' psychological health education model under Internet environment. There is no doubt that the Internet, with its unique characteristics and the strong function has sparked a new technology revolution, also shows the good digital paradise. But science and technology has always been a "double-edged sword", digital paradise bring the college students not only the joy and hope, at the same time also has the pain and frustration that caused the college students' psychological cognition, emotion, meaning, character and so on many changes. Under this basis, this paper combines the state-of-the-art research reviews to propose the new idea on the college students' psychological health education model that will promote the development path of the related research issues.

\section{References}

[1]. Saxton, John M., et al. "Effects of an exercise and hypocaloric healthy eating intervention on indices of psychological health status, hypothalamic-pituitary-adrenal axis regulation and immune function after early-stage breast cancer: a randomised controlled trial." Breast Cancer Research 16.2 (2014): 1.

[2]. Josefsson, Torbjörn, Magnus Lindwall, and Anders G. Broberg. "The effects of a short-term mindfulness based intervention on self-reported mindfulness, decentering, executive attention, psychological health, and coping style: examining unique mindfulness effects and mediators." Mindfulness 5.1 (2014): 18-35.

[3]. Timms, Carolyn, et al. "Flexible work arrangements, work engagement, turnover intentions and psychological health." Asia Pacific Journal of Human Resources 53.1 (2015): 83-103.

[4]. Lindström, Martin, Sadiq M. Ali, and Maria Rosvall. "Socioeconomic status, labour market connection, and self-rated psychological health: The role of social capital and economic stress." Scandinavian journal of public health 40.1 (2012): 51-60. 